Special Issue: Social Cognition and Self. Citation: West, A. (2015). A brief review of cognitive theories in gender development. Behavioural Sciences Undergraduate Journal, 2(1), 59-66.

Author: Alyssa West, Psychology, Mount Royal University (MRU)

Correspondence: awest164@mtroyal.ca

Reviewers: Alain Morin, PhD, MRU; Hanaa El Moghrabi

Editor: Famira Racy, MRU

Acknowledgements: The BSUJ acknowledges Dr. Dave Mumby from Concordia University for associate editorial contribution to this article.

Author Acknowledgements: I would like to thank the BSUJ, and all of the individuals who work tirelessly to ensure Mount Royal students have a platform on which to publish their writing. Specifically, I would like to thank Dr. Alain Morin, for his dedication to his students, and encouraging me to give my paper a chance to be published. Also, a big thank you to Famira Racy, the journal's Editor. Her guidance throughout this process has been valuable, and much appreciated. Finally, thank you to Tyler. His reassurances, along with his own motivation and focus, helped inspire me to work to the best of my abilities.

Copyright: (C) 2015 Alyssa West. This is an open-access article distributed under the terms of the Creative Commons Attribution 4.0 International License. The use, distribution or reproduction of this article in other forums is permitted, provided the original author(s) or licensor are credited, a link to the licence is provided (CC for 4.0), it is indicated whether or not changes were made to the original article, and other conditions of the BSUJ and the other forums are met.

\title{
A Brief Review of Cognitive Theories in Gender Development
}

\begin{abstract}
In this paper I review three cognitive theories that attempt to explain the mechanisms and processes through which we develop an understanding of gender. Cognitive-developmental theory, gender schema theory, and social cognitive theory of gender development and differentiation are compared in this article through the exploration of empirical evidence. Cognitive-developmental theory emphasizes the development of cognitive processes which allow for the understanding of gender. Gender schema theory highlights the active role schemas play in acquiring and interpreting gender relevant information, and social-cognitive theory stresses the role of the environment. I found that there is a considerable amount of overlap with the evidence between each theory. Therefore, rather than each theory existing in opposition to one another, there are multiple relevant factors at play concerning both cognition and the social environment in the development of gender. Thus, the main conclusion is that there is a need for greater theoretical integration with regard to understanding gendered development.
\end{abstract}

Keywords: Cognitive-developmental theory, gender schema theory, social cognitive theory, gender development, gender differentiation

\section{Introduction}

Society is gendered. It is organized around the division of biological sex into gendered binaries of man and woman (i.e., the two-sex model; Gannon, 2014). Briefly, the two-sex model refers to our understanding of people existing as two biologically dichotomous sexes (Guntram, 2013). However, this division extends beyond simple biology into socially and psychologically gendered maleness and femaleness, or masculinity and femininity. A common definition used to 
understand gender is that while sex is biological, gender is socially and psychologically constructed, referring to the given roles, behaviours, and characteristics deemed appropriate for either a man or a woman, as determined by social norms (Ryan, 2007). While these definitions of sex and gender seem relatively clear, they do not follow because the process through which we develop an understanding of our own gender is much more complex than assignment of sex.

Despite the difficulties involved in studying gender, it has remained a topic of great interest within social psychological research "largely because of its pervasive influence on social attitudes and behaviour" (O’Brien et al., 2002, p. 1008). Multiple theories propose different modes through which gender is learned, and while there is disagreement among them, most researchers agree that both cognitive processes and socialization are contributors (O'Brien et al., 2002). Therefore, in the present paper, three inter-related yet separate theories that include the processes of cognition and socialization regarding the development of gender are explored: social cognitive theory, cognitive-developmental theory, and gender schema theory. Each theory will be briefly described, and their relevance to children's understanding of gender explored through the examination of empirical evidence.

\section{Overview of Theories}

Each of these theories involves cognition, although not necessarily in the same manner. Cognitive-developmental theory highlights the importance of cognitive processes as they relate to the formation of gender constancy. Gender schema theory specifically emphasizes how the formation of schemas constructs both the meaning, and interpretation of gender-relevant information. Finally, social cognitive theory argues that cognition is important, insofar as it is involved in processing gender-relevant information from the surrounding environment. These are the common aspects of the theories that I am most interested in for this exploration.

\subsection{Cognitive-Developmental Theory}

Cognitive-developmental theory views the understanding of gender as the outcome of having passed through three stages of cognitive maturation that pertain specifically to gender. Martin, Ruble, and Szkrybalo, (2002) interpreted them as: (1) gender identity, or a child's growing understanding that they belong to either the category of boy or girl, (2) gender stability, or the realization that this gender identity does not change over time, and (3) gender consistency, or the understanding that gender identity is not directly affected by changes in appearance, activities, and characteristics.. This process is termed gender constancy; it is the gradual understanding that gender is fixed, and is an essential component of the cognitive-developmental approach. It argues that once a child has established gender constancy within themselves, gender categories become both more important and more relevant (Martin et al., 2002).

Another author describes this process in slightly different terms: (1) beginning awareness, (2) rigidity, and (3) flexibility (Trautner et al., 2005, p.365-366). These terms are similar to those described by Slaby and Frey (1975) and interpreted by Martin, Ruble, and Szkrybalo, (2002); therefore I argue their combined meaning may be explained as (1) growing awareness of the categories of male and female, and understanding that one must belong to one or the other, (2) understanding the categories of male and female as inflexible, with specific characteristics pertaining to each one, and (3) a gradual realization that in fact there is flexibility between characteristics belonging to males and females; in other words, there can be overlap between characteristics. Finally, cognitive-development theory postulates that "mastery or competence motivation is a driving force in gender development, as children seek to bring their 
perceptions and behaviours in line with their developing knowledge about gender categories” (Martin et al., 2002, p. 909). In other words, children recognize the importance of the gender binary, which motivates them to fit into their designated category.

In summary, cognitive-developmental theory focuses on how children socialize once they understand themselves as belonging either to the category of male or female (Bem, 1981). Therefore gender cognitions take precedence in this theory. Gender constancy is central in children's understanding of different aspects of gender, including knowledge of gender stereotypes, selective attention, and same-sex modeling (Martin et al., 2002).

\subsection{Gender Schema Theory}

Gender schema theory is a process where the schemas are active, facilitating a relationship between the child's thoughts, behaviour, and in turn shaping the development of their gender and attitudes towards the self. Proposed by Bem (1981), gender schema theory is "a theory of process, not content" (p. 356). The premise is that the manner in which children become sex-typed (i.e., embody specific characteristics and beliefs that are deemed appropriate for one sex but not the other) is through gender-based schematic processing. This is due to the self-concept assimilating into the gender schema (cognitive categorization of gender related information relevant to the self, e.g., attitudes, lifestyles, sexuality) as a consequence of learning from society which qualities they should and should not embody given their sex. Bem (1981) reasoned that self-esteem (i.e., self-evaluation) is implicated with gender schemas because children learn to compare themselves against their gender schema, evaluating their preferences, attitudes, behaviours, and personal attributes.

\subsection{Social Cognitive Theory of Gender Development and Differentiation}

Relevance of behavioural and cognitive factors is considered in this theory; however, primary emphasis is placed upon the environment and social practices in producing and perpetuating gender differentiation, particularly through modeling (Bussey \& Bandura, 1999). Specifically, social cognitive theorists argue that the development and differentiation of gender transpires through the reciprocal and bidirectional influences occurring between three factors: personal, behavioural, and environmental. Personal factors refer to gender-related cognitions, judgmental standards, and self-regulatory influences such as thoughts, evaluations, and decisionmaking. Behavioural factors account for overt actions linked to gender (e.g., flirting behaviours), and environmental factors are the numerous social influences experienced in every day interactions. Bussey and Bandura (1999) posit that this approach is different from gender schema theory and cognitive-developmental theory in that it specifically emphasizes the importance of non-cognitive related influences, specifically motivational, affective and environmental factors. In particular, it highlights the importance of learning gendered information through models. In their own words, Bussey and Bandura (1999) explain: "gender constancy is the product rather than an antecedent of the emulation of same sex models" (p. 688).

\section{Empirical Evidence for Socialization and Emotion}

Girls and boys are socialized differently in terms of which emotions they are taught as appropriate to express given their sex. For example, when a girl cries she is more likely to receive positive attention, whereas a boy is more likely to receive negative attention (Parmley \& Cunningham, 2008). Therefore, girls and boys are socialized differently in regards to the expression of feelings, in favor of that which is most befitting of their sex. For example, women 
are expected to have feminine and soft emotional expressions like crying, while men are expected to have masculine and hard expression like withholding tears, because soft emotions are associated with nurturing and hard emotions are associated with protection-traits assumed to be associated with being a woman or a man, respectively. Hence emotions are both stereotyped and gendered.

Some researchers are interested in the context in which children may utilize these genderemotion stereotypes because these are a type of schema. For example, Shields (1995) argued that the use of stereotypes is context dependent, and Robinson et al. (1998) found that stereotypes are more likely to be activated when the situation is ambiguous (as cited in Pamley \& Cunningham, 2008). Therefore, Parmley and Cunningham (2008) examined whether young children would utilize gender-emotion stereotypes when asked about a character's emotional experience in an emotionally ambiguous context (p. 360). Indeed, they found that even when the ambiguous context was held constant between male and female characters, preschoolers were more likely to perceive the male character as angry, and the female character as sad.

These results indicate that children's cognitions regarding emotions are stereotyped, and these stereotypes are more likely to be utilized within uncertain circumstances. This is indicative of support for gender schema theory, since the same information was given different meaning based on the character's gender. However, the social aspect in relation to cognition cannot be ignored. Socialization occurs simply through the manner in which parents speak about emotions with their children (Pamley \& Cunningham, 2008). Therefore, these researchers argue that emotional and social development probably has more than a significant relationship in that the factors may have an "inseparable" impact on one another (p. 359). Based on this interpretation, this study may be understood as support for both social cognition theory and gender schema theory.

\subsection{Ster eotype Development and Endorsement}

Signorella and Frieze (2008) sought to evaluate the developmental aspects of gender schemas. What they found was that, as Martin et al. (2002) have asserted, part of the developmental process with the cognitive-developmental approach involves a period of rigidity that later matures into flexibility (p. 909). Referring to the specific steps outlined previously, this may also be understood as moving from the second stage, gender stability, to the third stage, gender consistency. Therefore, Signorella \& Frieze (2008) compared the developmental trends between children and adolescents, finding stronger relations between gender-typed attributes (activity and occupational preferences) and gender-stereotype endorsement among children compared to adolescents. This pattern indicates an increasing level of stereotype flexibility over the early lifespan, thus providing support for the cognitive-developmental theory.

\subsection{Rigidity and Flexibility}

Trautner et al. (2005) intended to specifically examine the veracity of the cognitivedevelopmental theory assumption that all children will go through the same three-step process in their learning of gender, and that this can be seen through a period of gender recognition, followed by stereotype rigidity, and graduated flexibility. The authors collected longitudinal data from a sample of children, examining gender-stereotyped attributions in regards to behaviours and personality traits. While a period of initial rigidity was demonstrated between the ages of 5 and 7 , the findings further indicated that children follow a similar pattern of initial rigidity followed by increasing flexibility with age, regardless of the age which rigidity initially 
presented at, and how high the peak level of it was. The authors summarized their findings as they pertain specifically to the cognitive-developmental approach: "Our findings are consistent with a cognitive-developmental perspective on gender development, in the sense of suggesting that all children take basically the same path of waxing and waning of stereotype rigidity across development, despite variations in when it begins and at what level it reaches" (Trautner et al., 2005, p. 374). These findings provide specific and strong support for the development of gender cognitions occurring first through a period of fixed understanding of gender, then moving towards a more adaptable and open understanding.

\subsection{Recall}

With regards to gender schema theory, recall represents a memory bias in favor of gender-stereotypes because people seem to rely on gender-related information more than nongendered information when recalling memories and making judgments (Cherney, 2005). An implication of this bias is that it may facilitate encoding and retrieval of information that is relevant to one's own sex, while interfering with the recall of information that pertains to the opposite sex. Cherney (2005) sought to examine whether the presentation of stimuli and encoding conditions biased the gender schematic processing with children and adults in this way. Participants were randomly assigned to either an incidental memory condition (not told they would later need to recall), or an intentional memory condition (told they would later need to recall) where they later recalled images of toys representing either male, female, or neutral sex (Cherney, 2005).

The results were consistent with gender-schema theory; males recalled a significant amount more male stereotyped images of toys than those images representing female or neutral sex, whereas females recalled significantly more female and male stereotyped toys than neutral toys, although only in the incidental memory condition. Some argue that, in patriarchal societies, male stereotypes are learned separately from female ones since the male role is valued more in society (O'Brien et al., 2000). This could be one reason females recalled significantly more male stereotyped toys where males did not recall a significant amount of female ones. Nonetheless, each sex recalled gendered toys that were consistent with their own sex better than neutral ones, indicating presence of biased recall, consistent with gender-schema theory.

\subsubsection{Recall and Bias}

Frawley (2008) used the idea of biased judgment to evaluate the recall of gender-related information. Using gender schema theory, he explained that gender stereotypes prejudice children's memory, thus this cognitive bias maintains stereotypes and directs subsequent processing of gender specific information. Not only can gender schemas influence accurate recall, but may also incorporate false memories (Martin et al., 2004).

Frawley (2008) examined the effects of gender stereotypes on children's recall of two stories in evaluating how children remembered or distorted gender-specific information. The results showed a "wave of distortion" in that it seemed the children distorted their memories to make them more consistent with gender stereotypes (Frawley, 2008, p. 302). These findings thus support gender-schema theory, as they are evidence of biased judgment effects in the form of gendered stereotypes, and are therefore consistent with the assertion that gender schemas affect both the meaning of gendered information, and how it is interpreted. 


\subsection{Media}

According to social-cognitive theory, media can influence the behaviour of children through the observation of gender-stereotypical behaviour (Coyne, Linder, Rasmussen, Nelson \& Colier, 2014). Therefore, researchers evaluated the effect of viewing superhero television programs and movies modeling masculine behaviour on the play behaviours of preschool-aged girls and boys. The results indicated that younger boys are more likely to view programs and movies with superheroes, and after one year of viewing such programs, they engaged in more gender stereotyped play. Interestingly, this difference was not observed with girls who frequently watched media containing superhero characters compared to those girls who did not. The authors explain that this is in support of social-cognitive theory, since girls can learn about gender from viewing the behaviours of the opposite sex, but that this may not translate into play behaviour, where peer norms likely have a stronger influence. Further in support of social cognitive theory, these findings show how male superhero models can significantly influence the behaviour of young boys, yet not young girls (Coyne et al., 2014).

\subsection{Family and Parental Influence}

The familial influence cannot be ignored concerning the development of gender in young children. McHale, Crouter, and Tucker (1999) explained that both the familial experiences and context serve to inform gender stereotype development. One way in which the family directly influences the development of gendered understanding is through the stereotypes that the parents endorse, which may affect the development of their children's stereotypes. Accordingly, Endendijk et al. (2013) studied the effect of the gender stereotypes Mothers held on the adopted gender stereotypes of their preschool daughters. The results showed a significant relationship between mothers' and daughters' stereotypes. Mothers who had stronger gender stereotypes had daughters who also had stronger gender stereotypes. The authors explain that this result might have been observed because mothers may talk more about their interests and attitudes, and display gender-stereotypic beliefs with their daughters rather than sons (Endenjijk et al., 2013). Consequently, these results may be taken as support for social-cognitive theory, since the manner in which mothers socialize with their daughters affects the development of their gender stereotypes. Although, it must also be noted that additional factors must necessarily contribute, as there was no significant relationship observed between mothers' gendered beliefs and their sons, or between fathers and daughters.

\subsubsection{Sibling Influence}

While parental influence is important, siblings play a central role as well. Golombok, Hines, Johnston, and Golding (2000) sampled a large sample of girls and boys to see whether the presence of older siblings would influence gender role development in younger brothers and sisters as compared to only children. The results showed that the sex of the older siblings influenced the gender-role behaviours of the younger siblings. Specifically, boys with older brothers and girls with older sisters were more sex-typed than those children who had oppositesex siblings. Therefore, these results lend further support to the importance of gendered context in social-cognitive theory, providing an example of the influence of sibling modeling on gendered behaviour in children. 


\section{Conclusion}

This review is not exhaustive; rather, the purpose of this paper was to explore three current theories that pertain to the development of gender, with a specific focus on cognitive and social factors. While only a small selection of evidence was examined here, there is no shortage of persuasiveness within this evidence. However, each theory's generalizability is limited primarily to the western understanding of gender, hence it may be of both interest and value to explore more closely how cognitive and social factors are implicated with gendered understanding throughout other cultures. One option could be South East Asia, where a three-sex model is endorsed as opposed to the two-sex model (male and female) which we subscribe to (Gannon, 2014). For example, in India a third sex exists: the hijra. The identity of this group cannot simply be understood through a western lens of gender, and meaning is also lost through translation. Loosely, this group is made up of a third gender who are neither male nor female, but are liminal in that they can transcend borders of maleness and femaleness (Gannon, 2014).It is reasonable to assume that the cognitions and societal factors implicated within this culture may vary compared to our own, .

Empirical support was found for all three positions, although it must also be noted that there is a considerable amount of overlap with regards to each of the respective theories and the evidence. Furthermore, where one experiment may reinforce a particular theory, it may simultaneously weaken another, indicating that the results produced may partly dependent upon the given pursuit but may also depend partly on other factors. It is difficult, if not impossible, to definitively say that there is one causal factor that determines children's understanding of gender. Therefore, perhaps the pursuit should not be to determine which theory is the most accurate, but rather the recognition that each approach contains elements that help to deepen the understanding we have for how cognitive processes, as well as social ones, contribute to our gendered development. Future theories should therefore incorporate multiple factors pertaining to cognitive processes and socialization, and be able to adequately describe the potentially bidirectional relationship between the development of these two systems.

\section{References}

Bem, L. S. (1981). Gender Schema Theory: A Cognitive Account of Sex Typing. Psychological Review, 88, 354-364.

Bussey, K., Bandura, A. (1999). Social Cognitive Theory of Gender Development and Differentiation. Psychological Review, 106, 676-713.

Cherney, I. (2005). Children's and Adults' Recall of Sex-Stereotyped Toy Pictures: Effects of Presentation and Memory Task. Infant and Child Development, 14, 11-27.

Coyne, M. S., Linder, R. J., Rasmussen, E. E., Nelson, A. D., Collier, M. K. (2014). It's a Bird! It's a Plane! It's a Gender Stereotype!: Longitudinal Associations Between Superhero Viewing and Gender Stereotyped Play. Sex Roles, 70, 416-430.

Enjenjijk, J. J., Groenveld, G. M., van Berkel, R. S., Hallers-Haalboom, T. T., Mesman, J., BakermansKranenburg, J. M. (2013). Gender Stereotypes in the Family Context: Mothers, Fathers, and Siblings. Sex Roles, 68, 577-590.

Frawley, T. (2008). Gender Schema and Prejudicial Recall: How Children Misremember, Fabricate, and Distort Gendered Picture Book Information. Journal of Research in Childhood Education, 22, 291-303.

Gannon, S. (2014). Global Sexualities, South-East Asia. Retrieved from Mount Royal University SLGY 3233 Blackboard website: https://courseware.mymru.ca/webapps/portal/frameset.jsp?tab_tab_group_id=_2_1\&url=\%2Fweb 
apps\%2Fblackboard\%2Fexecute\%2Flauncher\%3Ftype\%3DCourse\%26id\%3D_193600_1\%26url $\% 3 \mathrm{D}$

Golombok, S., Hines, M., Johnson, K., Golding, J. (2000). The Role of Brothers and Sisters in the Gender Development of Preschool Children. Journal of Experimental Child Psychology, 77, 292-303.

Guntram, L. (2013). "Differently normal” and "normally different”: Negotiations of female and embodiment in women's accounts of 'atypical' sex development. Social Science \& Medicine, 98, 232-238.

McHale, S. M., Crouter, A. C., \& Tucker, C. J. (1999). Family context and gender role socialization in middle childhood: Comparing girls to boys and sisters to brothers. Child Development, 70(4), 990-1004.

Martin, L. C., Ruble, N. D., Szkrybalo, J. (2002). Cognitive Theories of Early Gender Development. Psychological Bulletin, 128, 903-933.

O’Brien, M., Peyton, V., Mistry, R., Hruda, L., Jacobs, A., Caldera, Y., \& Roy, C. (2000). Gender-Role Cognition in Three-Year-Old Boys and Girls. Sex Roles, 42, 1007-1025.

Parmley, M., Cunningham, G. J. (2008). Children's Gender-Emotion Stereotypes in the Relationship of Anger to Sadness and Fear. Sex Roles, 58, 358-370.

Robinson, M. D., Johnson, J. T., \& Shields, S. A. (1998). The gender heuristic and the database: Factors affecting the perception of gender related differences in the experience and display or emotions. Basic and Applied Social Psychology, 20, 206-219.

Ryan, Barbara. "Sex and Gender.” Blackwell Encyclopedia of Sociology. Ritzer, George (ed). Blackwell Publishing, 2007. Blackwell Reference Online. 15 January 2015

$<$ http://library.mtroyal.ca:2043/subscriber/tocnode.html?id=g9781405124331 chunk g97814051 2433125_ss1-81>

Shields, S. A. (1995). The role of emotion beliefs and values in gender development. In N. Eisenberg (Ed.) Review of personality and social psychology (Vol 15) (pp. 212-232). Thousand Oaks, CA: Sage Publications.

Slaby, R. G., \& Frey, K. S. (1975). Development of gender constancy and selective attention to same-sex models. Child Development, 52, 849-856.

Trautner, M. H., Ruble, N. D., Cyphers, L., Kirsten, B., Behrendt, R., Hartmann, P. (2005). Rigidity and Felxibility of Gender Stereotypes in Childhood: Developmental or Differential? Infant and Child Development, 14, 365-381. 